\title{
Factors influencing postoperative recurrence of Crohn's disease in childhood
}

\author{
A M Griffiths, D E Wesson, B Shandling, M Corey, P M Sherman
}

\begin{abstract}
We have reviewed the outcome of all patients undergoing their first intestinal resection for Crohn's disease at this hospital between 1970 and 1987. Recurrence rates, defined by recurrent intestinal symptoms and radiological confirmation of mucosal disease, were calculated using survival analysis. Age, sex, anatomical location of disease, indication for surgery, preoperative duration of symptomatic disease, use of preoperative bowel rest, and pathological features of the resected bowel were analysed individually and jointly as potential risk factors influencing postoperative recurrence of disease. Eighty two patients (age, mean (SD) 14.8 (2.5) years) underwent intestinal resection and were followed postoperatively for a minimum of one year (mean 5.3 (3.3) years). Anatomical location of disease, indication for surgery, and preoperative duration of symptomatic disease were the only factors that significantly influenced the duration of the recurrence free interval.
\end{abstract} Patients with diffuse ileocolonic inflammation experienced earlier recurrence $(50 \%$ at one year) than children with predominantly small bowel disease $(50 \%$ recurrence at five years, $\mathbf{p}<\mathbf{0 . 0 0 0 1 )}$. Failure of medical therapy independent of disease location as the sole indication for surgery was associated with an earlier relapse than when surgery was performed for a specific intestinal complication such as abscess or obstruction $(p<0.003)$. Patients undergoing resection within one year of onset of symptoms experienced delayed recrudescence of active disease (30\% recurrence by eight years) compared with patients whose preoperative duration of symptomatic disease was longer $(50 \%$ recurrence by four years when preoperative duration of disease was one to four years and $50 \%$ by three years when disease had been present greater than four years preoperatively, $p=0.03$ ). The mean height velocity of patients with growth potential increased from $2.4(2 \cdot 3) \mathrm{cm}$ per year preoperatively to $8.1(3.4) \mathrm{cm}$ per year in the first postoperative year $(p=0.0001)$. These results support an early approach to surgery in the management of ileal Crohn's disease with or without caecal or right colonic involvement, especially when complicated by persistent growth failure. The higher recurrence rates in more diffuse ileocolonic disease emphasise the need for alternative treatment strategies in these children.

The possibility of an appreciable asymptomatic interval after intestinal resection in Crohn's disease makes surgery an attractive treatment option, despite the likelihood of eventual disease recrudescence. ${ }^{1-5}$ This is particularly true for children and adolescents, in whom delays in growth and pubertal development are common and disturbing complications and for whom the adverse effects of steroids and the inconvenience of nutritional treatments frequently become unacceptable. Rates of recurrence ${ }^{1-5}$ and factors influencing postoperative recurrence of disease have been analysed ${ }^{6-12}$ for adult patients. Similar data for paediatric patients are required, as young age has been reported by some to affect outcome adversely. ${ }^{25} \mathrm{We}$, therefore, analysed the influence of age, sex, preoperative disease duration, indication for operation, anatomic location of disease, use of preoperative bowel rest, and specific pathological characteristics on cumulative postoperative recurrence free survival in a cohort of surgically treated children and adolescents with Crohn's disease.

\section{Methods}

The records of all patients undergoing their first intestinal resection for Crohn's disease at the Hospital for Sick Children during the years 1970-86 were reviewed retrospectively. Follow up data were obtained from the hospital records, by telephone contact with former patients, now young adults, and by correspondence with their current adult gastroenterologist.

Recurrence was defined as both the return of intestinal symptoms and radiological evidence of mucosal disease. Cumulative recurrence rates were calculated to correct for the varying lengths of follow up. ${ }^{13}$ Patients were considered as remaining at risk for recurrence from the time of initial operation until the last follow up contact or until the onset of symptoms ultimately proved to be due to recurrence of disease.

Patients were categorised according to sex, anatomic location of disease, indication for operation, use of preoperative bowel rest, preoperative duration of symptomatic disease, presence or absence of enteric fistulae, and presence or absence of granulomata in the resected bowel. Postoperative recurrence free survival curves for various subgroups were compared using Wilcoxon and log rank statistics. All calculations were performed with computer program SAS using the Lifetest procedure..$^{13}$ Age and duration of symptoms were included as covariables in all comparisons.

The effect of surgery on growth was studied by comparing pre- and postoperative height centiles and height velocities in patients who were prepubertal (Tanner stage 1) or in early puberty (Tanner stage 2 or 3 ) at the time of intestinal resection. The charts of Tanner and Whitehouse ${ }^{14}$ were used to determine height centiles. 
Standard deviation scores for observed height velocities were calculated according to the following equation:

$$
\text { Standard deviation score }=\frac{\chi-\bar{\chi}}{\mathrm{S}_{\mathrm{x}}}
$$

where $\chi$ is the observed height velocity, $\bar{\chi}$ the mean height velocity for the given age and sex, and $S_{x}$ the standard deviation of that mean. The $\bar{\chi}$ and $S_{x}$ for a given age and sex were obtained from the Fels longitudinal study data. ${ }^{15}$

\section{Results}

Between 1970 and 1987, 89 patients with Crohn's disease, out of a total of 275 followed at the inflammatory bowel diseases clinic, underwent their first intestinal resection at this hospital. Primary reanastamosis was carried out in all but five children (two with colonic and three with extensive ileocolonic Crohn's disease), who had an ileostomy created at the time of resection. There was one late postoperative death because of a series of septic complications. Six patients were lost to follow up within the first postoperative year. The remaining 82 surgically treated patients were followed for a mean (SD) of 5.3 (3.3) years. Mean age at the time of operation was 14.8 years (range 5.9-19.0 years). The median postoperative recurrence free interval for the entire group was $5 \cdot 1$ years. Wilcoxon and log rank statistics had similar probability levels within each analysis, suggesting that the differences observed are general and not confined to an early postoperative period. Therefore, log rank $\chi^{2}$ tests are presented in this report.

\section{ANALYSIS OF FACTORS POTENTIALLY INFLUENCING RECURRENCE}

Sex

The recurrence-free survival curves were similar for the 48 boys and 34 girls (log rank $\chi^{2}=0.3$, $\mathrm{p}=0.6)$. The median postoperative recurrence free interval was $5 \cdot 1$ years for boys and $5 \cdot 0$ years for girls.

\section{Anatomical site of disease}

The largest group of patients undergoing intestinal resection consisted of 46 with disease confined to the terminal ileum, with or without caecal involvement. Ten patients had more proximal and often more extensive small bowel disease, but a normal colon. Both the distal ileum and the colon were abnormal in 24 patients. Of these 24 , colonic inflammation was limited to the right colon in eight, but was diffuse and extensive in 16. Only two children had disease confined to the colon, precluding any useful analysis of this subgroup.

As shown in Figure 1, recurrence rates for patients with extensive ileocolonic disease were strikingly different from those of the three other anatomical subgroups $\left(\chi^{2}=22.6, \mathrm{p}<0.0001\right)$. The median disease free interval was only one year for patients with extensive ileocolonic disease compared with five years for those with terminal ileal disease with or without caecal

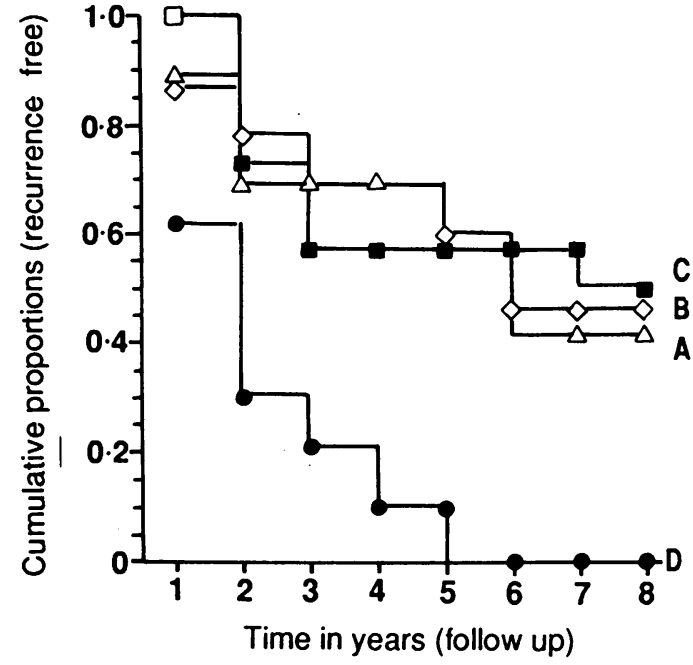

$\begin{array}{lllllllll}\text { A } & \frac{1}{10} & \frac{2}{9} & \frac{0}{7} & \frac{0}{6} & \frac{1}{6} & \frac{0}{5} & \frac{1}{4} & \frac{0}{1} \\ \text { B } & \frac{6}{46} & \frac{4}{38} & \frac{3}{27} & \frac{0}{18} & \frac{2}{15} & \frac{2}{9} & \frac{0}{5} & \frac{0}{4} \\ \text { C } & \frac{0}{8} & \frac{2}{8} & \frac{1}{5} & \frac{0}{3} & \frac{0}{3} & \frac{0}{3} & \frac{0}{3} & \frac{0}{2} \\ \text { D } & \frac{6}{16} & \frac{5}{10} & \frac{1}{4} & \frac{1}{2} & \frac{0}{1} & \frac{1}{1} & \end{array}$

Figure 1: Cumulative postoperative recurrence free surviva according to anatomical site of disease. $A=$ small bowel; $B=$ terminal ileum \pm caecum; $C=$ terminal ileum + ascending colon; $D=$ extensive ileocolonic. In this and the two subsequent figures, the numbers below the abscissa indicate, for each year of follow up study, the numbers of recurrences within the preceding year over the number of patients still followed and at risk during that year. Two year and five year disease free survival rates with $95 \%$ confidence intervals are: group $A 0.70(0.42-0.98)$ and $0.58(0.27-0.90)$; group $B$ $0.78(0.66-0.90)$ and $0.60(0.43-0.77)$; group $C 0.73$ $(0.42-1.05)$ and $0.57(0.20-0.94)$; and group $D 0.30$ $(0.07-0.52)$ and $0.11(0.08-0.29)$.

inflammation, six years for the small bowel group, and eight years for patients with disease in the terminal ileum and ascending colon.

\section{Indication for operation}

Indications for intestinal resection are summarised in Table I. Forty six patients were treated surgically for one or more intestinal complications including bowel obstruction, intra-abdominal abscess, enterovesicular or enterocutaneous fistula, perforation, and major haemorrhage. The variation in frequency of intestinal complications necessitating operation according to anatomical site of Crohn's disease is shown in Table I. In 31 patients resection was

TABLE I Indication for operation according to anatomical site of disease

\begin{tabular}{|c|c|c|c|}
\hline \multirow[b]{2}{*}{$\begin{array}{l}\text { Anatomical site } \\
\text { of disease }\end{array}$} & \multirow[b]{2}{*}{$\begin{array}{l}\text { No of } \\
\text { patients }\end{array}$} & \multicolumn{2}{|c|}{ Indication for operation } \\
\hline & & $\begin{array}{l}\text { Specific } \\
\text { intestinal } \\
\text { complication }\end{array}$ & $\begin{array}{l}\text { Failure of } \\
\text { medical } \\
\text { therapy }\end{array}$ \\
\hline Small bowel & 10 & 6 & 4 \\
\hline $\begin{array}{l}\text { Terminal } \\
\text { ileum } \pm \text { caecum }\end{array}$ & 43 & 35 & 8 \\
\hline $\begin{array}{l}\text { Terminal ileum + right } \\
\text { colon }\end{array}$ & 8 & 2 & 6 \\
\hline $\begin{array}{l}\text { Extensive ileocolonic } \\
\text { Total }\end{array}$ & $\begin{array}{l}16 \\
77^{\star}\end{array}$ & $\begin{array}{r}3 \\
46\end{array}$ & $\begin{array}{l}13 \\
31\end{array}$ \\
\hline
\end{tabular}

$\star$ Total surgical group excluding three patients operated on for diagnosis before any medical treatment and two patients with isolated colonic disease. 
Figure 2: Cumulative postoperative recurrence free survival according to indication for operation. Group 1: operation for specific intestinal complication (obstructive or perforating). Group 2: operation for failure of medical therapy without specific intestinal complication. Two year and five year disease free survival rates with $95 \%$ confidence limits are: group 1 $0.80(0.68-0.92)$ and $0.60(0.43-0.77) ;$ group 2 $0.49(0.31-0.65)$ and 0.35 $(0 \cdot 17-0 \cdot 53)$

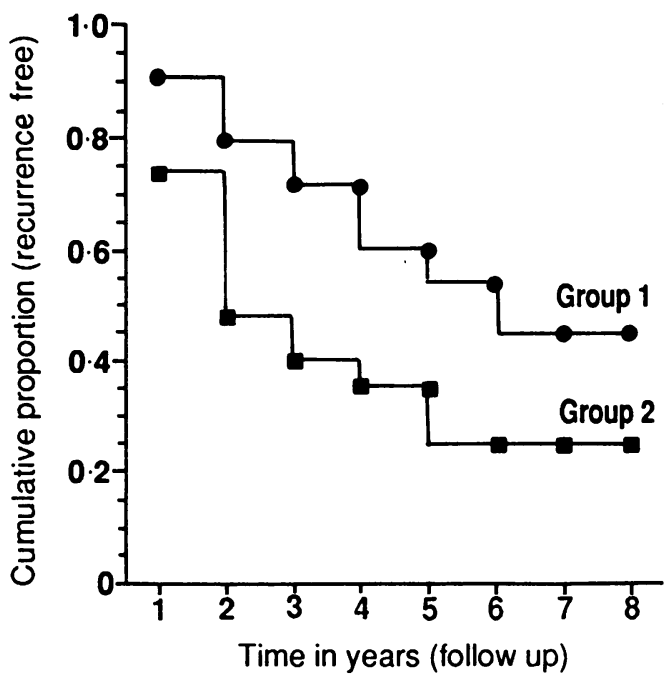

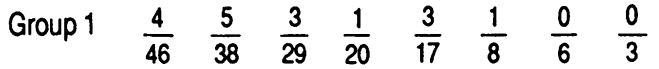

$\begin{array}{llllllll}\text { Group } 2 & \frac{10}{34} & \frac{7}{23} & \frac{3}{11} & \frac{0}{7} & \frac{1}{7} & \frac{1}{6} & \frac{0}{5}\end{array}$

performed because of failure of medical treatment, without a specific intestinal complication. Growth failure was never the sole indication for resection, but when present it frequently influenced the clinical decision that a patient had 'failed' medical treatment. Three patients came to operation for diagnosis before any medical treatment. In these children there was concern about a radiological appearance consistent with malignancy in two and suspected acute appendicitis in one.

As shown in Figure 2, patients undergoing resection for a specific intestinal complication enjoyed a longer postoperative recurrence free interval (median of 6 years) than the children

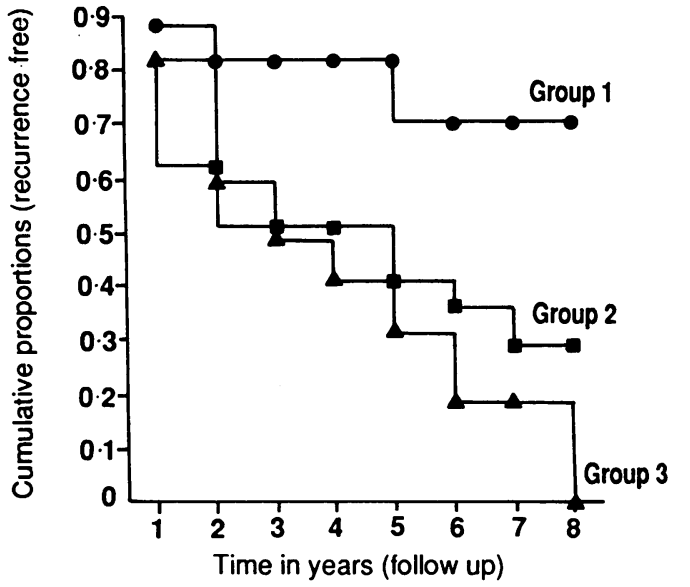

$\begin{array}{lllllllll}\text { Group 1 } & \frac{2}{17} & \frac{1}{14} & \frac{0}{12} & \frac{0}{11} & \frac{0}{9} & \frac{1}{7} & \frac{0}{3} & \frac{0}{2} \\ \text { Group 2 } & \frac{7}{38} & \frac{7}{29} & \frac{3}{17} & \frac{0}{11} & \frac{2}{10} & \frac{1}{8} & \frac{1}{5} & \frac{0}{3} \\ \text { Group 3 } & \frac{4}{23} & \frac{5}{18} & \frac{2}{11} & \frac{1}{6} & \frac{1}{4} & \frac{1}{2} & \frac{0}{1} & \end{array}$

Figure 3: Cumulative postoperative recurrence free survival according to duration of preoperative symptomatic disease.

Group 1: preoperative disease of less than one year's duration. Group 2: one to four years of preoperative disease and Group 3: preoperative disease of greater than four years' duration. Two year and five year disease free survival rates with $95 \%$ confidence limits are: group $10.82(0.64-1.00)$ and $0.82(0.64-1.00)$; group $20.62(0.46-0.78)$ and 0.41 $(0.23-0.60)$; and group $30.60(0.40-0.80)$ and $0.32(0.09$ $0 \cdot 56)$. who had simply failed medical treatment (median recurrence free survival of 1.7 years) $\left(\log \operatorname{rank} \chi^{2}=8.8, \mathrm{p}<0.003\right)$. Within each anatomic subgroup a similar trend was observed.

\section{Pathologic features}

Twenty six patients (32\%) had evidence of an internal fistula in the resected bowel. The rate of recurrence among these children did not differ significantly from the remaining 56 patients who did not have fistulous disease $\left(\log \operatorname{rank} \chi^{2}=1 \cdot 7\right.$, $\mathrm{p}=0 \cdot 2$ ). Similarly granulomata were found in $67 \%$ of surgical specimens, but their presence or absence did not correlate with postoperative outcome $(p=0 \cdot 4)$.

\section{Preoperative bowel rest}

Total parenteral nutrition or nasogastric tube feeding of an elemental diet was used for longer than one week to provide preoperative bowel rest in 38 patients $(45 \%)$. The rate of recurrence in this group was no different from that observed among patients who did not receive this treatment. The median recurrence free survival time was five years in both groups (log rank $\chi^{2}=0.0002, \quad p=0.99$ ).

\section{Duration of preoperative disease}

Duration of symptomatic disease before intestinal resection was analysed as a covariable in each of the previous comparisons. Shorter periods of preoperative illness were associated with later recrudescence of active disease among patients stratified according to anatomical site of disease $(p \simeq 0.05)$ and indication for resection $(p<0.02)$. Figure 3 shows that this finding was due to a significantly longer disease free interval among the patients whose symptoms had begun less than one year before surgery. Their median recurrence free survival time was greater than eight years (only $30 \%$ recurrence by eight years). Patients with preoperative disease duration of one to four years and greater than four years experienced $50 \%$ recurrence by four and three years respectively $\left(\log \operatorname{rank} \chi^{2}=7 \cdot 0, \mathrm{p}=0.03\right)$.

Age

Age was also analysed as a covariable in all other comparisons and did not influence recurrence free survival.

\section{EFFECT OF SURGERY ON GROWTH}

Preoperative and postoperative growth data are presented according to Tanner stage, in view of the normal variation in growth velocities expected during puberty. Thirty patients were either prepubertal (Tanner stage 1) or in early puberty (Tanner stage 2) at the time of intestinal resection. Height velocity in the one year preoperatively was available for 22 of these children, and postoperative height velocity was recorded for 28. These data are shown in Figure 4 and Table II. Data for the eight patients in Tanner stage 3 at the time of surgery are similar (Table II). 


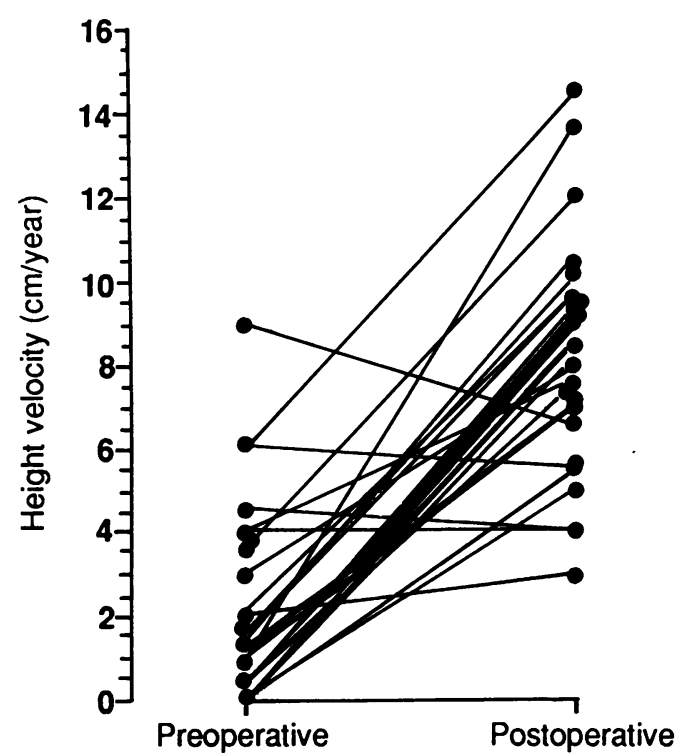

Figure 4: Comparison of pre-and postoperative height velocity in patients Tanner stage 1 or 2 at the time of intestinal resection.

The 38 patients in Tanner stage 1,2 or 3 increased from a mean (SD) height centile of $11 \cdot 1$ $(12.6)$ at the time of resection to an ultimate $(n=26)$ or current $(n=12)$ height centile of $29 \cdot 5$ $(27 \cdot 5)(\mathrm{p}<0.001)$

\section{Discussion}

The natural tendency of Crohn's disease to recur after resection is well documented. ${ }^{1-5}$ The importance of considering cumulative rather than crude recurrence rates ${ }^{3}$ and of carefully defining 'recurrence" has been emphasised frequently. Macroscopic disease in the neoterminal ileum was identified endoscopically in $72 \%$ of patients who underwent routine colonoscopy one year after intestinal resection in a recent prospective study. ${ }^{16}$ Most studies of postoperative outcome have defined recurrence as either need for reoperation or, as in our study, symptomatically and radiologically. The latter definition will obviously be associated with higher rates of recurrence. ${ }^{1}$ Our choice of symptomatic recurrence with radiological corroboration was based on the importance to young patients of an interval of freedom from illness, particularly before completion of growth. Furthermore, indications for reoperation may have been altered considerably by the increasing use of nutritional treatments as alternative medical treatment.

The overall recurrence rate of $50 \%$ by five years in our series of 82 children and adolescents is relatively high compared with previously docu-

TABLE II Comparison of preoperative and postoperative growth data

\begin{tabular}{|c|c|c|c|c|c|c|}
\hline \multirow[b]{2}{*}{ Score } & \multicolumn{2}{|c|}{$\begin{array}{l}\text { Height velocity } \\
\text { (cm/year) }\end{array}$} & \multicolumn{2}{|l|}{$\begin{array}{l}\text { Mean SDS } \\
\text { height velocity }\end{array}$} & \multicolumn{2}{|l|}{ Height centile } \\
\hline & 1 year preop & 1 year postop & 1 year preop & 1 year postop & At operation & At follow up $\ddagger$ \\
\hline $\begin{array}{l}\text { Tanner 1, } \\
2 \text { patients } \\
(\mathbf{n}=30)\end{array}$ & $2 \cdot 5(2 \cdot 4)^{\star}$ & $8 \cdot 2(2 \cdot 7) \dagger$ & $-1.62(1.40)^{\star}$ & $+1.52(1.71) \dagger$ & $10 \cdot 4(10 \cdot 5)$ & $29 \cdot 1(26 \cdot 3)$ \\
\hline $\begin{array}{l}\text { Tanner } 3 \\
\text { patients } \\
(\mathrm{n}=8)\end{array}$ & $2 \cdot 2(2 \cdot 4)$ & $7 \cdot 6(5 \cdot 3)$ & $-0 \cdot 12(0 \cdot 80)$ & $+4 \cdot 39(5 \cdot 32)$ & $13 \cdot 8(19 \cdot 5)$ & $31 \cdot 1(33 \cdot 4)$ \\
\hline
\end{tabular}

SDS denotes standard deviation score. All results expressed as mean (SD).

^ Based on 22 patients; †based on 28 patients; fall Tanner 3 patients were followed to their adult height: 12 Tanner 1 and 2 patients were still growing at the time of follow up. mented rates in adult populations as recently summarised by Shivananda et al. ${ }^{12}$ In most of these studies, however, rates of reoperation rather than of symptomatic and radiological recurrence were recorded. Greenstein et $a l^{3}$ analysed recurrence rates using criteria similar to ours and found a $60 \%$ cumulative recurrence rate at five years. The young mean age of patients (24 years) was one of the factors postulated to account for this comparatively high recurrence rate. Others have also suggested that a young age at the time of resection is associated with earlier recurrence. ${ }^{2}$

In our study, the anatomical site of Crohn's disease was the most important factor influencing the rate of its recrudescence. Patients with extensive ileocolonic disease had a preponderance of early recurrences after intestinal resection. A previous study of patients undergoing resection in childhood also noted a higher cumulative rate of recurrence among children with ileocolonic disease. ${ }^{17}$ Lock $e t a l$ also found reoperation rates to be much higher in adult patients with ileocolic disease than in those with disease confined to either the small bowel or the large bowel alone. The extent of colonic inflammation did not influence the relatively high rate of recurrence in their patients with ileocolonic disease $^{7}$ but our data suggest that it does. In contrast to the Cleveland group's original report, ${ }^{7}$ both their subsequent study of a larger, more recent cohort of patients ${ }^{10}$ and the study of Sachar $e t a l$ f failed to find a statistically significant difference in recurrence rates among subgroups stratified according to anatomical distribution of disease.

Our patients were assigned an anatomical classification on the basis of the preoperative radiological assessment and the operative findings, which occasionally identified previously unrecognised sites of involvement. We recognise that superficial mucosal inflammation might well be overlooked. The concept of Crohn's disease as a panenteric inflammatory condition has emerged with and been supported by endoscopy and examination of endoscopic biopsy specimens. This does not negate the usefulness of classification according to anatomical extent of gross disease in predicting clinical patterns and guiding management. ${ }^{18}$

Sachar et $a l^{p}$ stressed the importance of considering the inter-relation of different variables before attributing a difference in recurrence rates to one factor. Our patients with extensive ileocolonic disease had a somewhat longer preoperative mean duration of symptomatic disease ( 3.7 years) than patients with predominantly small bowel disease $(2 \cdot 4$ years $)$. This primarily reflects a reluctance to subject young patients to extensive resections. Patients with extensive ileocolonic disease did not otherwise differ from the remainder except with respect to indication for operation (Table I).

Our analysis of the influence of indication for operation on the rate of disease recrudescence suggests that the presence of an intestinal complication as the primary indication for resection is predictive of a better postoperative outcome than when surgery is performed for disease deemed generally refractory to medical treatment (Fig 2). 
Although this finding was strongly related to the preponderance of patients with ileocolonic disease among those undergoing resection without specific intestinal complication (Table I), the same trend was observed for patients in each anatomical subgroup. In patients with terminal ileal disease with or without caecal involvement, intestinal complications were equally distributed between obstructive and perforating - that is fistulas, abscess, free perforation. Our data are reassuring, therefore, that even perforating complications do not justify pessimism about an increased risk of early postoperative recurrence. The explanation for a shorter postoperative disease free interval among patients without an intestinal complication is unclear. One might speculate that any complication, be it obstructive or fistulous, serves to localise disease.

Greenstein $e t a l^{19}$ reported a more rapid rate of reoperation among patients undergoing their first resection for a perforating as opposed to a non-perforating indication such as intestinal obstruction, haemorrhage, and medical intractability. In contrast to our study, perforating indications for operation were more common in their ileocolitis group than in the regional enteritis or Crohn's colitis group. Furthermore, the effect of the anatomical site of disease on reoperation rates was not considered. Whelan et $a l^{10}$ found the presence of an internal fistula to be associated with a higher likelihood of recurrence in their total surgical group, but the correlation did not reach statistical significance within anatomical subgroups. Again, in their series internal fistulas were more frequently present in ileocolitis than in small bowel or colonic Crohn's disease.

The influence of preoperative duration of symptomatic disease on the length of the postoperative disease free interval (Fig 3) seems to be in direct contrast to a similarly designed study in adults. Sachar et al' reported that preoperative disease of shorter duration is associated with earlier recurrence, suggesting the existence of inherently more aggressive and more indolent forms of Crohn's disease. Others have found no significant correlation between preoperative disease duration and time to recurrence. ${ }^{512}$ Our observation of a longer postoperative asymptomatic interval among patients with a shorter duration of illness preoperatively may be unique to paediatrics.

The effect of surgical intervention on growth was very favourable (Fig 4; Table II). Similar improvements in growth after surgery for childhood Crohn's disease were reported previously $^{172021}$ and included an earlier cohort of patients at our own hospital..$^{22}$ It is evident, however, that an early recurrence of disease could inhibit this positive short term effect on growth velocity. ${ }^{23}$ Nevertheless, the ultimate height centile of our patients increased over the height centile at the time of resection (Table II). We do not have sufficient data about heights before illness to determine whether true "catch up' growth ${ }^{24}$ occurred. The beneficial effect on growth, while certainly attractive, should not be the sole factor considered in a decision to operate on growth impaired children with Crohn's disease. Nutritional intervention, if sustained, yields a comparable improvement in growth velocity. ${ }^{25}$

Our data on postoperative outcome and factors influencing Crohn's disease recrudescence support an early operative approach in patients with disease localised to the small bowel, even with right colon involvement, but not if more diffuse colonic disease coexists. The excess of early recurrences among patients with extensive ileocolitis suggests that alternative medical and nutritional strategies should be attempted and maintained in this group.

The results of this study were presented in part at the International Falk Symposium on Pediatric and Surgical Gastroenterology: Inflammatory Bowel Disease and Celiac Disease held in Basel, Switzerland, November, 1989.

1 Lennard-Jones JE, Stalder GA. Prognosis after resection of chronic regional ileitis. Gut 1967; 8: 332-6.

2 deDombal FT, Burton I, Goligher JC. Recurrence of Crohn's disease after primary excisional surgery. Gut 1971; 12: 51927.

3 Greenstein AJ, Sachar DB, Pasternack BS, Janowitz HD. Reoperation and recurrence in Crohn's colitis and ileocolitis. N Englf Med 1975; 293: 685-90.

4 Nygaard K, Fausa O. Crohn's disease: recurrence after surgical treatment. Scand f Gastroenterol 1977; 12: 577-84.

5 Hellers G. Crohn's disease in Stockholm county 1955-74. A study of epidemiology, results of surgical treatment and long-term prognosis. Acta Chir Scand 1979; 490 (suppl): 31 70 .

6 Mekhijian HS, Switz DM, Watts D, Deren JJ, Katon RM, Beman FM. National cooperative Crohn's disease study: factors determining recurrence of Crohn's disease after surgery. Gastroenterology 1979; 77: 907-13.

7 Lock RM, Farmer RG, Fazio VW, Jagelman DG, Lavery IC Weakley FL. Recurrence and reoperation for Crohn's disease. The role of disease location in prognosis. $N$ Engl $\mathcal{f}$ Med 1981; 304: 1586-8.

8 Wolfson DM, Sachar DB, Cohen A, et al. Granulomas do not affect postoperative recurrence rates in Crohn's disease. Gastroenterology 1982; 83: 405-9.

9 Sachar DB, Wolfson DM, Greenstein AJ, Goldberg J, Styczunski R, Janowitz HD. Risk factors for postoperative recurrence of Crohn's disease. Gastroenterology 1983; 85: 917-21.

10 Whelan G, Farmer RG, Fazio VW, Goormastic M. Recurrence after surgery in Crohn's disease. Relationship to location of disease (clinical pattern) and surgical indication. Gastroenterology 1985; 88: 1826-33.

11 Chardavogne R, Flint BW, Pollack S, Wise L. Factors affecting recurrence following resection for Crohn's disease. Dis Colon Rectum 1986; 29: 495-502.

12 Shivananda S, Hordijk ML, Pena AS, Mayberry JF. Crohn' disease: risk of recurrence and reoperation in a defined disease: risk of recurrence and

13 SAS Institute. SAS User's Guide: Statistics. 5th ed. Cary NC: SAS Institute Inc, 1985.

14 Tanner JM, Whitehouse RH, Takaishi M. Standards from birth to maturity for height, weight, height velocity, and weight velocity: British Children, 1965. Part I. Arch Dis Child 1966; 41: 454-71.

15 Baumgartner RN, Roche AF, Himes JH. Incremental growth tables: supplementary to previously published charts. $A m \mathcal{F}$ Clin Nutr 1986; 43: 711-22.

16 Rutgeerts P, Geboes K, Vantrapper G, Kerremans R Coenegrachts JL, Coremans G. Natural history of recurrent Crohn's disease at the ileocolonic anastamosis after curative surgery. Gut 1984; 25: 665-72.

17 Castile RG, Telander RL, Cooney DR, et al. Crohn's disease in children: assessment of the progression of disease, growth and progress. $\mathcal{F}$ Pediatr Surg 1980; 15: 462-9.

18 Farmer RG, Hawk WA, Turnbull RB Jr. Clinical patterns in Crohn's disease: a statistical study of 615 cases. Gastroenterology 1975; 68: 627-35.

19 Greenstein AJ, Lachman P, Sachar DB, et al. Perforating and non-perforating indications for repeated operations in Crohn's disease: evidence for two clinical forms. Gut 1988; 29: 588-92.

20 Block GE, Moossa AR, Simonowitz D. The operative treatment of Crohn's disease in childhood. Surg Gynecol Obstet ment of Crohn's

21 Alperstein G, Daum F, Fisher SE, et al. Linear growth following surgery in children and adolescents with Crohn's following surgery in children and adolescents with Crohn's
disease. Relationship to pubertal status. $\mathcal{F}$ Pediatr Surg 1985; 20: 129-33.

22 Wesson DE, Shandling B. Results of bowel resection for Crohn's disease in the young. $\mathcal{F}$ Pediatr Surg 1981; 16: 44952.

23 Homer DR, Grand R, Colodny AH. Growth, course and prognosis after surgery for Crohn's disease in childhoood Pediatrics 1977; 59:717-25.

24 Forbes GB. A note on the mathematics of 'catch up' growth Pediatr Res 1974; 8: 929-31.

25 Aiges H, Markowitz J, Rosa J, Daum F. Home nocturna supplemental nasogastric feedings in growth-retarded adolescents with Crohn's disease. Gastroenterology 1989; 97 905-10. 